\title{
Por que uma convenção sobre a proteção da diversidade cultural?
}

ANTONIO A. DAYRELL DE LIMA

$\mathrm{U}$ MA CONVENÇão internacional sobre diversidade cultural está, no momento, em negociação na Unesco, instituição cuja razão essencial é o diálogo intercultural, que, por sua vez, é bastante exacerbado pelo fenômeno da globalização... A rationale básica dessa negociação é determinar o quadro jurídico internacional consensual para a proteção da diversidade cultural na era da globalização. Nesse sentido, a indesejável homogeneização das culturas é inelutável?

Reconheçamos: com a globalização, as culturas de massa de inspiração exógena passaram a fazer parte, em caráter definitivo, dos costumes mundiais. Seria tão fútil legislar de forma impositiva contra esse fenômeno, em nome do particularismo nacional, da moral ambiente ou da política, quanto legislar contra a lei da oferta e da procura. O exemplo das transformações ocorridas no ex-bloco socialista ou na China Popular estão aí.

Mesmo os mais ferrenhos alter-globalistas estão plenamente conscientes disso, já que utilizam os mecanismos da rede planetária e propõem justamente uma mundialização “outra”, não negando em si, portanto, o fenômeno precípuo da interdependência... Temos também já um século da "obra de arte na época da reprodução técnica" e estamos (quase todos) conectados, de uma forma ou outra, mundialmente. Portanto, a Cultura - com C maiúsculo - perdeu muito do seu elitismo e é hoje um negócio de vulto.

Os mais realistas dirão que é evidente que, mesmo nos dias de hoje, o reconhecimento em escala global de alguns valores universais e a homogeneização de práticas técnicas ou econômicas não significa necessariamente acabar com todas as particularidades que constituem a riqueza (ou a miséria) do gênero humano, nem equivale a anunciar a morte da arte e da alta cultura, tradicionalmente o domínio das elites.

Mas assunto não é banal: afeta conceitos políticos fundadores. Com a globalização, por exemplo, o próprio conceito de soberania nacional vem evoluindo. Mas, com uma interdependência global acrescida, há efeitos, inclusive o cultural, que ultrapassam as conseqüências que seriam aceitáveis para uma redefinição mínima do papel do Estado na matéria, já que estas perturbam as próprias relações entre nações ou esvaziam as tramas sociais sobre as quais se assentam as bases políticas. Manifestamente, o Estado não deve ter o monopólio das idéias fundadoras da sociedade, mas também não aceitará ficar impotente diante dos efeitos de cartéis culturais que a modifiquem, sobretudo se vindos de fora. 
À atenuação contemporânea do monopólio da forca pelo Estado - atributo essencial da soberania - a julgar pelo aumento do crime organizado, dos exércitos de mercenários privados ou do terrorismo, correspondem também com efeito outros enfraquecimentos relativos, tão preocupantes quanto estes... Com o surgimento de novos importantes focos de irradiação cultural, são igualmente criadas novas tramas de influência e de solidariedade, outros emblemas ou elementos totêmicos que concorrem com as fontes simbólicas, antes únicas, que garantiam tradicionalmente os elos entre poder, povo, governo, lei e nação.

Não se trata tampouco de discutir cegamente, reagindo com ufanismo ou xenofobia, à origem, em determinada civilização, do fenômeno da globalização das trocas, sejam elas materiais ou imateriais. Os orientais e médios-orientais estão totalmente conscientes e convencidos da superioridade de suas respectivas civilizações, inclusive do ponto de vista material, em um largo período histórico; interpretam os "atrasos" que vieram a sofrer apenas como decorrentes de fatores políticos. Com efeito, para um não ocidental, pode ser evidente que o Ocidente tem a propensão de ignorar que o Positivismo e o mercantilismo neoliberal modernos tem sua genealogia no messianismo cristão medieval que, aliado à normativa política e jurídica herdada dos romanos, impôs pela força das armas a primeira visão moderna mundial, a partir dos Descobrimentos. Para um ocidental, no entanto, provavelmente a globalização pode ser vista apenas como um fenômeno da simples superioridade tecnológica e científica, a partir das Luzes do século XVIII, cujo bonde certas civilizações perderam. Para um ex-colonizado tipicamente dividido quanto à sua identidade, as marcas indeléveis do domínio e da importação cultural exógena, em sua história nacional, possivelmente tem elementos tanto negativos como positivos, a maioria trágicos e alienantes, assim como alguns, ao contrário, foram modernizadores e benéficos para a sociedade. O espectro é infinito, justamente porque, em matéria cultural, a norma é a pluralidade e a diferença - e é fácil exacerbá-las.Toda civilização, como o indivíduo, tem seu ponto-cego, seu super-ego e uma auto-imagem que os estrangeiros não enxergam...

Seria igualmente ingênuo não aceitar que os elementos técnicos da globalização não sejam utilizados, como já o são, por outras importantes fontes culturais, por motivos econômicos ou políticos, que nada tem a ver com o modelo atual "americano/ europeu" da modernização neoliberal.

Os espectros dos fundamentalismos e da imposição de valores pouco democráticos, todos eles não são temíveis por constituírem em si um obscurantismo, uma regressão histórica ou um atual contrasenso político-filosófico no mundo contemporâneo, mas sim principalmente porque estes movimentos vistos como "medievais" justamente entenderam os mecanismos da modernidade e a atração, para as massas, da mensagem identitária e cultural.

Além disso, vale ressaltar que existem espasmos de expansão e retração na globalização, do ponto de vista da abertura recíproca à interpenetração cultural, 
os quais afetam sua própria "imagem de marca" e ideologia. Alguns refletem os vagares do mercado, outros, tendências societais profundas. O momento atual do Centro Globalizador parece ser o de ir em frente, mas, se protegendo, interna e externamente, da Periferia, enquanto a despreza ou a domina. Nem sempre foi assim e uma globalização sem alguma reciprocidade, entendida apenas como simples hegemonia cultural, pode ser tentada, mas não é realista a médio prazo, do ponto de vista orgânico e sistêmico. A interdependência nunca é uma mão única. Aliás, existe claramente, no momento, desde o 11 de setembro 2001, uma insegurança conceitual no Ocidente com relação à definição estratégica do que significa a globalização - além de enriquecer a curto prazo as multinacionais, é claro.

Em particular, o projeto estratégico nacional norte-americano parece hoje estar dividido entre o ideal tradicional da convergência global em torno dos seus valores culturais, contra o de uma simples imposição unilateral (é melhor ser temido do que ser amado), ambos apimentados por uma excepcionalidade no tratamento internacional que lhe garanta, no século XXI, a continuação de seu predomínio. Neste ambiente, é evidente que a mensagem cultural que era contida na "Pax Americana" anteriormente proposta perde sentido e força... Surgem curiosos paralelos (ou até alianças) entre fundamentalismos transoceânicos que esvaziam a pressuposta superioridade da "racionalidade" sistêmica moderna e científica ocidental sobre outras culturas tradicionais. Cria-se, inclusive, um cisma dentro da mensagem globalizante ocidental entre neoconservadores e os de outras tendências, tanto à esquerda ou quanto à direita, cisma este que se assenta mais sobre motivos culturais do que politicos.

Necessitamos hoje de limites para que possam ser balizadas as trocas culturais internacionais, se não quisermos aceitar a imposição de um novo mundo orwelliano ou se não desejarmos dar razão ao catastrofismo de Samuel Huntington no tocante ao "conflito de civilizações".

A exemplo do ocorrido na esfera ambiental, está se produzindo assim, no campo da cultura, o mesmo tipo de "descoberta" mundial tardia de uma nova temática global. Já há algum tempo, a Unesco, ONGs e redes de Ministros da Cultura de determinados países agitavam a necessidade de se disciplinar os impactos da indústria cultural na era da globalização. O pano de fundo eram temores de hegemonias, aspirações de novos produtores, fracassos na OMC e velhas oposições conceituais. Em 2001, a Unesco adotaria assim a Declaração Universal sobre a Diversidade Cultural. Hoje persegue-se o instrumento internacional mandatório, com uma Convenção.

O que mudou desde 2001? Mudou a percepção da realidade política internacional: ela é hoje mais "antropológica".

A discussão sobre o tema - cuja origem data de 1970, após a última onda de descolonização, com a oposição entre dirigismo cultural e liberdade de expressão, matéria para muita ideologia - havia se refugiado, após a derrocada do bloco 
soviético, em uma tertúlia essencialmente econômica entre neoliberais e menos liberais, acerca de quão além poderia ir a indústria cultural, no caminho traçado pelo livre-comércio. Criava-se a OMC, começava-se a discutir "serviços" e dispositivos como o Trips e o Gatts. Estavam em jogo, sobretudo, os interesses das majors do cinema e do audiovisual, assim como os dos países emergentes. Os itens quentes eram "mercado", "propriedade intelectual", "subsídios" ou "investimentos".

Da agenda política internacional, estava evacuada a discussão do lastro cultural que impulsiona o ativismo político. Morta a ideologia, dominava o mercado: ganhara finalmente Reagan, que, aliás, havia retirado os Estados Unidos da Unesco, e os louros da globalização tranqüila caberiam a seus sucessores, que todos formulariam um futuro de convergência em torno da prática e do "sonho" americanos.

Hoje, esse lastro reaparece e os governos se inquietam, talvez tardiamente, sobretudo com as "paixões" culturais que estruturam psicodramas nas sociedades, inclusive com a intolerância religiosa, dentro de uma visão mais "antropológica" do que a Realpolitik autorizava. Um ano depois do 11 de setembro, o governo norte-americano anunciava que re-integraria a Unesco, após vinte anos...

Não se discute, aqui, o fato de que a cultura moderna esteja no âmago do fenômeno da globalização - e igualmente ninguém seria suficientemente tolo para desprezar a importância econômica da indústria moderna dos sonhos (segunda, nos EUA, depois a dos armamentos), que constituem o poder de convencimento e cooptação (soft-power), essencial para as nações contemporâneas, que produzem cada vez mais no setor de serviços e entretenimento. Além de tudo, deveríamos também reconhecer que são freqüentemente os sonhos que impulsionam os povos na direção de um futuro melhor.

Sejamos cautelosos, no entanto, já que a globalização não é aparentemente (numa visão ingênua) apenas um processo técnico historicamente inelutável, que torna tudo homogêneo e mais simples. Do ponto de vista moral e funcional, ele, aliás, é particularmente imperfeito e complexo, já que põe em marcha uma maior interdependência entre sociedades e nações desigualmente vulneráveis, criando assim muitas novas desigualdades e exclusões.

Mas, na verdade, a era moderna que a globalização atual propaga é, sobretudo, e antes de mais nada, uma criação de expectativas. É um paraíso prometido, mas não de uma forma religiosamente hermética ou para outra vida, é o aqui e agora do outdoor bem gráfico, bem terreno. A propaganda de massa moderna é necessariamente ideal e pretensamente igualitária. Todos são levados a conhecer e apreciar a mercadoria, inclusive como símbolo de status social. Não existe mais o "isto não é para mim" de antigamente. Mas poucos poderão adquiri-la, a não ser numa versão de segunda ou de terceira classe, mas que carrega o símbolo, o emblema da marca, o Logo (que permite pertencer a uma nova tribo)... Não existe mais a "distinção" que depende da raridade do produto, é a "distinção" 
mesma que é prometida com o produto talismã, em suas várias versões, para cada indivíduo da massa. Mas é um paraíso onde a maioria dos contemplados vão, em última análise, para o purgatório e disto se ressentem. Mata-se por um modelo novo de tênis.

Verdadeiro “culto à carga" (o fenômeno antropológico curioso dos melanésios que cultuavam aviões de palha que seriam propiciatórios à distribuição mágica de mercadorias) a idéia em si de globalização já é uma mensagem desestabilizadora que chega sempre antes do mensageiro. Tem um efeito de demonstração ou se transforma em profecia auto-realizadora, com enormes conseqüências. Ao perseguir objetivos materiais legítimos, podemos tornar obsoletas as "redes de significados que o homem tece e aos quais está suspenso" (Geertz), assim introduzindo a anomia e o caos na periferia e no Quarto Mundo.

O drama planetário que vivemos não é justamente esse, o da negação freqüente da identidade própria, ou até da genealogia fundadora do povo ou da nação - reforçada pelas exclusões sociais ou econômicas ambientes - diante de uma cultura de massa freqüentemente exógena, que aniquila todos os referenciais familiares com seus baixos preços, sua atração ou talento de evasão? Culturas "dignas" mas pobres, com efeito, perdem todo o seu auto-respeito e dignidade emblemática nos grotões rurais esquecidos ou nas favelas urbanas - onde aliás a mídia e o sonho de consumo global nunca estão ausentes. O palpável empobrecimento das culturas, neste contexto - o de culturas ricas de tradição, mas vulneráveis por sua falta de recursos - não é, portanto, uma denúncia vazia. As pessoas desaprendem tudo, até a sobreviver com dignidade. A marginalização e a exclusão, que leva à perda da própria identidade, é hoje um problema social global grave e o principal motor da violência, gerando o suicídio ou o crime.

A necessidade da proteção da trama cultural não exprime, portanto - como alguns críticos alarmistas afirmam -, apenas a negação sistemática do discurso do livre-comércio que introduziria generosas idéias de modernização e democracia. Decorre de devastações reais, causadas pela onda global, com toda a voracidade do darwinismo econômico, que agora se exerce, em última análise, na esfera dos valores e das idéias. Temo que haja infelizmente, em nossa época, um descolamento planetário indevido e catastrófico - passageiro, espero eu - entre a esfera econômica e a social, bem como uma monetarização excessiva da cultural.

Podemos legitimamente falar, portanto, no mundo complexo das transações culturais atuais, da necessidade de uma ação afirmativa (afirmative action) internacional, para evitarem-se os desvios que, até agora, não puderam ser corrigidos. Claramente, a cultura, por sua própria natureza, não pode ser objeto de transações que a transformem em simples commodity, como já bem se disse e redisse. A lei das vantagens comparativas, que motiva toda a filosofia livre-cambista, dificilmente poderia ser aplicada com rigor na esfera cultural internacional. Os mercados culturais são particularmente singulares e imperfeitos, estando sujeitos a todo tipo de dumping e distorções intrínsecas. E é obviamente inconce- 
bível e contraprodutivo, mesmo sob critérios de puro Box-Office, que se discuta a matéria cultural unicamente sob a ótica do financiador... Torna-se evidente, portanto, que devemos aceitar alguma margem de exceção para as transações internacionais dos conteúdos culturais e das expressões artísticas.

Dessa forma, não existe forçosamente o antagonismo entre as posturas aqui defendidas e as veiculadas na OMC, já que elas se referem - idealmente - a duas esferas complementares. O que pode haver em jogo é o que há sempre em toda negociação, ou seja interesses nacionais e setoriais divergentes... As negociações na Unesco iluminarão necessariamente a matéria como um todo, em vez de configurarem um empecilho para o diálogo intercultural ou o próprio comércio cultural. Estamos longe da tentativa de se estabelecer, como se tentou ingenuamente há vinte anos atrás, em plena Guerra Fria, uma Nova Ordem Internacional da Informação.

O Brasil - cabe precisar - por sua formação histórica é um país aberto, acolhedor e pluralista. Somos uma síntese intercultural e não somente um mosaico de culturas. Sabemos, também, que o livre fluxo de idéias é o nosso passaporte para a independência e a democracia. Reconhecemo-lo como garantia ao respeito dos Direitos Humanos, que foram restabelecidos no Brasil. Portanto, podemos sem complexos criticar a desordem ou a falsa ordem que o "mercado das estrelas" pretende manter ou impor; temos também que defender a industria nacional, valorizar e proteger nossa cultura, paliando às suas vulnerabilidades, $\mathrm{e}$ brecar as tentativas políticas de se manipular a questão.

Sob o anúncio de uma era cultural que se quer universal, onde a ideologia teria sido abolida (esta é mais uma profecia cíclica), na realidade, vislumbra-se hoje um panorama preocupante para as trocas interculturais, criador de todo tipo de chauvinismos ou de reações simétricas a estes e eminentemente predador.

Evidencia-se, claramente, uma freqüente falta de transparência, com estereótipos e amálgamas, assim como uma banalização da má-fé nesse campo. Instaurou-se também uma certa desproporção megalomaníaca nas industrias culturais, numa evidente falta de equilíbrio, com a formação inaudita de verdadeiros oligopólios ou cartéis culturais. Lida-se hoje, portanto, com um mercado que, por meio de suas singularidades ou imperfeições, em sua estrutura e práticas, impõe um denominador comum muitas vezes esterilizante e castrador. Freqüentemente, chega-se assim a uma total pobreza conceitual, em decorrência de critérios puramente comerciais, que podem provocar inclusive no público sentimentos de invasão, de perdas de identidade ou de alienação, particularmente entre os mais jovens e os desfavorecidos.

Perduram, entretanto, como prioritários - em todas as nações, porque fazem parte de seu desenvolvimento político próprio - vários aspectos em contradição flagrante com este quadro pessimista. Refiro-me à persistência dos imperativos dos valores endógenos, da valorização do pluralismo, do reconhecimento de minorias, dos direitos à diferença e, sobretudo, da obrigação de zelarmos pela 
proteção dos atributos socioculturais identitários. Persiste, portanto, o direito soberano à regulação ou à limitação das ingerências exógenas descabidas ou dos efeitos de uma lógica puramente comercial na esfera cultural. Estas são prioridades incontestáveis, em cada âmbito nacional.

Mas os aspectos negativos, acima citados, freqüentemente dominam sobre estas prioridades... Só agora está se começando a dar a devida importância ao conceito mais geral de patrimônio cultural, além do monumento ou da singularidade natural (no caso, o patrimônio imaterial). O desejo do novo, em si compreensível, quando aliado ao mercantilismo crasso que desconsidera a história ou a paisagem, não necessariamente é, aliás, um problema único aos países em desenvolvimento.

Tudo isto explica, por si só, a necessidade de uma negociação internacional mais conseqüente sobre o tema.

Já em 2003, nos pronunciamos finalmente e favoravelmente a que a Unesco viesse a elaborar uma Convenção sobre a Diversidade Cultural, manifestando assim nossas preocupações além do plano puramente comercial. Já existe o seu primeiro rascunho.

Perderemos, naturalmente, algum tempo discutindo se devemos sobretudo defender a "liberdade cultural" (o direito de mudar de cultura, curiosamente defendido por neo-conservadores ocidentais, mas que pode também ser interpretado como simples direito a consumir os produtos da modernidade) ou a "proteção dos valores culturais" (que precisa ser detalhada, já que engloba, no mesmo saco, tanto a exceção cultural defendida pela "velha Europa" e Canadá, a defesa por asiáticos de seus grandes mercados audiovisuais e de seus particularismos neo-capitalistas não muito democráticos - os famosos Asian Values - e a blindagem tentada por sociedades todavia mais tradicionalistas, que temem sua desestabilização pelo soft-power de outrem. Onde nos situamos nesta negociação?

O Brasil tem no assunto, naturalmente, um bom "cacife" diplomático e se beneficiará de uma imagem bem mais favorável do que exibia quando se iniciaram, por exemplo, as discussões ambientais nos anos de 1970. Por sua própria experiência intercultural relativamente mais sincrética e convival, por ser um país emergente dotado de um setor audiovisual já importante, por ser o repositório de um enorme mercado, por ter como idioma uma língua materna muito singular, mas que é hoje mais falada do que o francês - por todos estes motivos, o Brasil está fadado a exercer, como já vem exercendo, um papel fundamental nesta negociação.

Buscaremos, dentro de nossas prioridades, o consenso, mas sempre a partir de certos pressupostos que hoje estão consagrados como "civilizados", por nós e na prática internacional. Teremos necessariamente que ter um enfoque que suprima o perigo da instrumentalização do relativismo cultural para fins politicos. Devemos evitar toda manobra que resulte no atentado à livre circulação de idéias, ao diálogo intercultural ou que sirva de pretexto para a regressão antidemocrática 
ou que, mais simplesmente, dê seu aval ao desrespeito dos Direitos Humanos, a pretexto dos valores de uma cultura tradicional imutável.

Estas são algumas das chaves principais do tratamento da questão da diversidade cultural, tema que não mobilizou muito até hoje nossa sociedade civil, mas que é fundamental, já que ela é a essência da nacionalidade, em particular, da brasileira.

Antonio A. Dayrell de Lima é embaixador brasileiro e delegado permanente do Brasil junto à Unesco.

Texto recebido em 10/11/2004 e aceito em 18/1/2005. 